\title{
Mass Spectrometric Detection of Affinity Purified Crosslinked Peptides
}

\author{
Gregory B. Hurst \\ Chemical Sciences Division, Oak Ridge National Laboratory, Oak Ridge, Tennessee, USA \\ Trish K. Lankford and Stephen J. Kennel \\ Live Sciences Division, Oak Ridge National Laboratory, Oak Ridge, Tennessee, USA
}

Chemical crosslinking of proteins combined with mass spectrometric analysis of the tryptic digest of the products shows considerable promise as a tool for interrogating structure and geometry of proteins and protein complexes. An impediment to the use of this tool has been the difficulty of distinguishing crosslinked peptide pairs from non-crosslinked peptides, and from the products of side reactions. We describe the use of a commercially available biotinylated crosslinking reagent, sulfo-SBED, that allows affinity-based enrichment of crosslinked species. An intramolecular crosslink is prepared using the peptide neurotensin as a model system. Matrix-assisted laser desorption/ionization time-of-flight (MALDI-TOF) mass spectra show the predicted crosslinking product, as well as several side products. Finally, we describe the optimized enrichment of biotinylated species, and reduction of non-specific binding, for a batch-mode affinity separation based on immobilized monomeric avidin. (J Am Soc Mass Spectrom 2004, 15, 832-839) (c) 2004 American Society for Mass Spectrometry

$\mathrm{C}$ hemical crosslinking is an established tool for studying protein structure and protein-protein interactions [1-4]. Crosslinking reagents introduce new covalent bonds into the three-dimensional (3D) structure of a protein or protein complex. The locations of these new bonds, along with the length and reactivity of the crosslinking reagent, provide lowresolution information on spatial relationships in the original 3D structure of the protein or protein complex $[2,5-7]$. However, determining the locations of the bonds introduced by the crosslinking reagent has proven to be a fairly difficult analytical task.

The recent growth of mass spectrometry (MS) capabilities for protein and peptide analysis have led to exploration of the utility of MS for elucidating locations of new covalent bonds introduced into proteins by chemical crosslinking reagents [1, 5, 8-10]. One strategy is to introduce crosslinks into a protein, digest the protein, and obtain peptide masses by MS, or peptide fragmentation patterns by tandem MS. Both noncrosslinked peptides and crosslinked pairs of peptides will be represented in the mass spectrum; the latter could in principle be recognized by comparison with the mass spectrum from a digested, but noncrosslinked, sample of the protein.

Published online April 15, 2004

Address reprint requests to Dr. G. B. Hurst, Chemical Sciences Division, Oak Ridge National Laboratory, P.O. Box 2008, MS 6131, Oak Ridge, TN 37831-6131, USA. E-mail: hurstgb@ornl.gov

This article was presented in part at the 51st Annual ASMS Conference on Mass Spectrometry and Allied Topics, Montreal, Quebec, Canada.
However, several practical limitations prevent the facile implementation of this strategy. Yields of crosslinking reactions may be low because of the necessity to avoid excessive crosslinking, which could distort the structures of the proteins under study. Because of this need to keep the number of crosslink events low (on the order of one per protein molecule [5]), large numbers of peptides in the subsequent enzymatic digest will not contain a crosslink. These peptides, which are not of primary utility for analysis of crosslinking products, constitute an interference to the detection of crosslinked peptide pairs. Additionally, side reactions to the crosslinking introduce non-informative peptides. For instance, only one end of a bifunctional crosslinking reagent might attach to the protein, while the other end undergoes hydrolysis, to yield an adduct on the protein ("surface labeling" or "single-ended" crosslinking).

In addition to these difficulties inherent to the mass spectrometric measurement of crosslinked peptide pairs, further complications arise in extracting information on crosslinked peptide pairs from mass spectrometry data. A polypeptide with $n$ enzymatic cleavage sites has $N=\sum_{x=1}^{n+1} x$ possible cleavage products if incomplete cleavage is considered. If $f$ is the fraction of these cleavage products containing a potential reactive site for the crosslinker, there are $\sum_{y=1}^{(5 N)-1} y$ different possible intramolecular crosslinked peptide pairs. For example, a protein with 10 enzymatic cleavage sites will have 66 possible complete and incomplete digest fragments; if one fifth of these contain a crosslinker-reactive site, 
there will be 78 possible crosslinked pairs of peptides. A protein with 20 cleavage sites will have 231 possible digest peptides and 1035 possible crosslinked pairs. The number of possible crosslinked peptides is thus fairly large, and grows rapidly with the number of cleavage sites. Furthermore, this number would be roughly squared for intermolecular crosslinking between two proteins. While not all these crosslinked peptides will be observed due to the chemical and geometric selectivity of the crosslinking reaction, they must all nonetheless be considered in interpreting experimentally observed $m / z$ values, as must surface-labeling products and non-crosslinked peptides. Accordingly, several computer programs have been described to aid in the analysis of mass spectra obtained from crosslinked, digested proteins $[3,5,10,11]$.

Several methods have been described for distinguishing crosslinked peptide species in mass spectra of crosslinked and digested proteins. Some of these methods use isotopically-labeled crosslinkers [12, 13] or proteins [14] that yield a distinctive signature in the mass spectrum. Chemical [15, 16] or isotopic [17] methods for post-digestion labeling the termini of peptides provide another type of mass spectrometric signature for differentiating and separating crosslinked peptide pairs from non-crosslinked or single-end crosslink derivatized peptide species. A chemical or isotopic label on a peptide or protein offers the possibility of distinguishing "single-ended" crosslinks from full crosslinks, while labels on the crosslinking reagents themselves do not. Crosslinking reagents that fragment under collision-induced dissociation conditions to yield a characteristic low-mass marker ion allow identification of peptides containing crosslinks [18, 19]. Although not related to mass spectrometric detection, a fluorescent tag on the crosslinker allows identification of crosslinked proteins in gel separations [20].

These techniques rely on the observation of a characteristic pattern in the mass spectrum or tandem mass spectrum of the analyte mixture. However, if the signalto-noise ratio of the crosslinked species yielding this pattern is insufficient, the pattern cannot be reliably discerned. The presence of "uninformative" peptides (vide supra), combined with low concentrations of crosslinked species, can thus thwart the measurement. Therefore, a separation method for enriching the analyte mixture in the crosslinked species would be useful for reducing levels of non-crosslinked peptides while simultaneously increasing the concentration of crosslinked species in the analyte mixture. An affinity separation provides such an advantage, as demonstrated by Trester-Zedlitz et al. [21]. The biotin-avidin interaction is a logical choice for this affinity separation; a biotin-labeled crosslinker can be extracted, along with its attached peptide(s), from a complex peptide mixture using an immobilized avidin separation medium. The relatively small size of the biotin moiety does not greatly increase the mass of a crosslinker, thereby minimizing both steric hindrance problems in the crosslinking reaction, and negative effects on the mass spectrometric measurement. The high affinity of biotin for avidin should improve the selectivity of the measurement.

In this paper, we describe a model system for separating biotinylated, crosslinked peptides from tryptic digests of crosslinked proteins. This system is based on the reaction between the peptide neurotensin (pGluLeu-Tyr-Glu-Asn-Lys-Pro-Arg-Arg-Pro-Tyr-Ile-Leu) and a commercially-available crosslinker, sulfo-SBED (sulfosuccinimidyl-2-[6-\{biotinamido\}-2-\{p-azidobenzamido\}hexanoamido]ethyl-1,3'-dithiopropionate). Sulfo-SBED, chosen primarily because it contains a biotin moiety, is a heterobifunctional crosslinker, incorporating an N-hydroxysuccinimide (NHS) ester that is reactive toward primary amines [22] and a photoactivatable aryl azide group that typically inserts into $\mathrm{N}-\mathrm{H}$ or $\mathrm{C}-\mathrm{H}$ bonds with accompanying loss of $\mathrm{N}_{2}[1,22,23]$. A disulfide bond in sulfo-SBED allows cleavage of the crosslink using thiol reagents. The primary amine on the single lysine side chain is the only position to which the NHS group of sulfo-SBED can attach, as there is no primary amine at the N-terminus (pyroglutamic acid). The photoactive arylazide group of sulfo-SBED can presumably attach anywhere on the neurotensin, within the constraints of the sulfo-SBED linker arm length. The expected product of the reaction between sulfo-SBED and neurotensin was observed, along with more abundant side reaction products. Although the model system of neurotensin and sulfoSBED differs from a crosslinked protein in that the peptide is much smaller than a protein, and the arylazide group can attach non-selectively, this simple system allowed examination of crosslinked reaction products without congestion of the mass spectrum by other peptides. Finally, we describe optimization of an avidin affinity separation of sulfo-SBED-crosslinked neurotensin from non-biotinylated peptides.

\section{Experimental}

\section{Reagents}

Sulfo-SBED and Immunopure immobilized monomeric avidin beads were purchased from Pierce (Rockford, IL). Organic solvents were HPLC grade. Water was either from a Millipore (Bedford, MA) system, or HPLC grade (Burdick and Jackson, Muskegon MI). Dithiothreitol (DTT), iodoacetamide, neurotensin, bovine hemoglobin and buffer components were used as received (Sigma, St. Louis MO). $\alpha$-Cyano-4-hydroxycinnamic acid (CHCA, Aldrich, Milwaukee, WI) was recrystallized from ethanol before use. Immobilon NC Pure nitrocellulose was obtained from Millipore. Sequencing grade modified trypsin was used as supplied by Promega (Madison, WI). Bovine serum albumin was from ICN Biomedicals (Aurora, $\mathrm{OH}$ ). 


\section{Crosslinking}

Neurotensin was dissolved at $1 \mathrm{mg} / \mathrm{mL}$ in phosphate buffer (0.1 M phosphate, $\left.0.18 \mathrm{M} \mathrm{Na}^{+}, \mathrm{pH} 7.5\right)$. SulfoSBED was weighed and dissolved in the same buffer under subdued light immediately before use. $100 \mu \mathrm{L}$ of the neurotensin stock was combined with $50 \mu \mathrm{L}$ of 4.4 $\mathrm{mg} / \mathrm{mL}$ sulfo-SBED for results in Figures 1 and 3; 100 $\mu \mathrm{L}$ of the neurotensin stock was combined with $20 \mu \mathrm{L}$ of $5 \mathrm{mg} / \mathrm{mL}$ sulfo-SBED for results shown in Figure 2 . Neurotensin and sulfo-SBED solutions were combined in 96-well microtiter plates and maintained under subdued light with aluminum foil wrapping for 30-60 min at room temperature to allow reaction with primary amines. $2 \mu \mathrm{L}$ of $1 \mathrm{M}$ Tris ( $\mathrm{pH}$ 8) was added to each reaction to hydrolyze unreacted NHS groups. A $365 \mathrm{~nm}$ UV lamp (Rad-Free Model RF UV-365, Schleicher and Schuell, Keene, NH, equipped with an $8 \mathrm{~W}$ bulb, model BLE760B, Spectronics, Westbury NY), held $\sim 5 \mathrm{~cm}$ distant from sample solutions, was used to activate the arylazide portion of the crosslinker. Samples were reduced by adding DTT to a final concentration of $50 \mathrm{mM}$ and incubating for $1 \mathrm{~h}$ at room temperature. Following reduction, selected samples were derivatized by incubation for $1 \mathrm{~h}$ in the dark with $50 \mathrm{mM}$ iodoacetamide.

\section{Digestion of Hemoglobin}

Bovine hemoglobin was digested to provide a set of "background" peptides. Hemoglobin was dissolved at 2 $\mathrm{mg} / \mathrm{mL}$ in $50 \mathrm{mM}$ Tris buffer, $\mathrm{pH} 8$, and denatured by heating for $1 \mathrm{~h}$ at $60{ }^{\circ} \mathrm{C}$ in $6 \mathrm{M}$ guanidine $\mathrm{HCl}$. The sample was diluted with 5 volumes of $50 \mathrm{mM}$ Tris buffer ( $\mathrm{pH} 8)$, and trypsin was added at a mass ratio of 50:1 (hemoglobin:trypsin). The sample was incubated overnight at $37^{\circ} \mathrm{C}$. A MALDI-TOF mass spectrum obtained after the digestion showed a substantial peak for trypsin at $m / z 23722$, but the signal due to intact $\alpha$ and $\beta$ hemoglobin chains was negligible, indicating nearcomplete digestion (data not shown). In order to prevent subsequent tryptic degradation of avidin, peptides were isolated from intact trypsin by passing the digest solution through a 10,000 Da MWCO centrifugal filter (Microcon YM-10, Millipore), retaining the flowthrough.

\section{Affinity Chromatography}

Avidin affinity capture of biotinylated species was performed using immobilized monomeric avidin. Small batches (typically $100 \mu \mathrm{L}$ ) of beads in 50\% aqueous suspension were prepared for use by washing with 400 $\mu \mathrm{L}$ of $0.1 \mathrm{M}$ phosphate buffer $\left(\mathrm{pH} 7.5,0.18 \mathrm{M} \mathrm{Na}^{+}\right)$, and collecting the beads by centrifuging at $2000 \mathrm{~g}$ for $3 \mathrm{~min}$. The beads were washed with $400 \mu \mathrm{L} 0.1 \mathrm{M}$ glycine $(\mathrm{pH}$ $2.8)$, collected, and washed again with $400 \mu \mathrm{L}$ phosphate buffer. The beads were then incubated with end-over-end rotation for $30 \mathrm{~min}$ in $2 \mathrm{mM}$ biotin in phosphate buffer, collected, and incubated for $30 \mathrm{~min}$ in $1.5 \mu \mathrm{M}$ bovine serum albumin in phosphate buffer. The beads were washed and collected successively from 400 uL $0.1 \mathrm{M}$ glycine buffer, $400 \mu \mathrm{L} 10$ or $20 \%$ methanol in $50 \mathrm{mM} \mathrm{NH}_{4} \mathrm{HCO}_{3}$, and $400 \mu \mathrm{L}$ phosphate buffer.

$50 \mu \mathrm{L}$ of a 1:100 dilution of the crosslinking reaction originally containing $250 \mathrm{nmol}$ sulfo-SBED and $60 \mathrm{nmol}$ neurotensin was combined with $50 \mu \mathrm{L}$ of the purified tryptic digest of hemoglobin. This mixture was combined with $20 \mu \mathrm{L}$ of a $50 \%$ slurry of prepared avidin resin in an $0.2 \mathrm{~mL}$ tube, and incubated for $3 \mathrm{~h}$ at room temperature with end-over-end rotation. The beads were collected, washed one to three times with $100 \mu \mathrm{L}$ phosphate buffer, and once with 10 or $20 \%$ methanol in $50 \mathrm{mM} \mathrm{NH} \mathrm{HCO}_{3}$. Biotinylated species were eluted from the beads using several $10-\mu \mathrm{L}$ portions, or one $100-\mu \mathrm{L}$ portion, of $50 \%$ acetonitrile in aqueous $0.4 \%$ trifluoroacetic acid. Acetonitrile was removed via two rounds of adding one volume of water and reducing by approximately half the volume of the eluate using a Speedvac AES1000 centrifugal vacuum concentrator (Savant, Holbrook, NY). The resulting aqueous eluate was prepared for MALDI analysis by purification using a C18 ZipTip (Millipore); ZipTip purification was also performed prior to MALDI on aliquots of the original sample solution, and on supernatants from intermediate wash steps in the avidin separation.

\section{Mass Spectrometry}

Matrix-assisted laser desorption/ionization (MALDI) mass spectra were obtained using a PerSeptive Biosystems Voyager Elite DE time-of-flight mass spectrometer equipped with a nitrogen laser (Applied Biosystems, Framingham, MA). Spectra were obtained in reflector mode, with $+20 \mathrm{kV}$ total accelerating voltage, $+15 \mathrm{kV}$ applied to the grid, $+1 \mathrm{kV}$ applied to the guide wire, and a $140 \mathrm{~ns}$ acceleration delay. Spectra are averages of up to 256 individual laser pulses, obtained from several locations on each sample spot. Sample aliquots were applied to a pre-spotted thin-layer matrix, prepared by drying $0.5 \mu \mathrm{L}$ portions of $5 \mathrm{~g} / \mathrm{L}$ nitrocellulose, $20 \mathrm{~g} / \mathrm{L}$ $\alpha$-cyano-4-hydroxycinnamic acid in 1:1 isopropanol: acetone to the sample plate [24]. Internal calibration of the $m / z$ axis was performed using known peptide species.

\section{Results and Discussion}

\section{Identification of Reaction Products}

Scheme 1 shows a number of the possible products of the reaction between sulfo-SBED and neurotensin, including a "full" intramolecular crosslink (first column), attachment of only the arylazide photoreactive group to neurotensin (second column), and single-ended reaction of NHS with the neurotensin lysine (third column). Oxidized analogs of sulfur-containing products in Scheme $\mathbf{1}$ are indicated by an "ox" subscript. Scheme $\mathbf{1}$ also shows products of subsequent reactions with dithiothreitol (DTT) and iodoacetamide, which were performed to verify the structures of the crosslinked neu- 


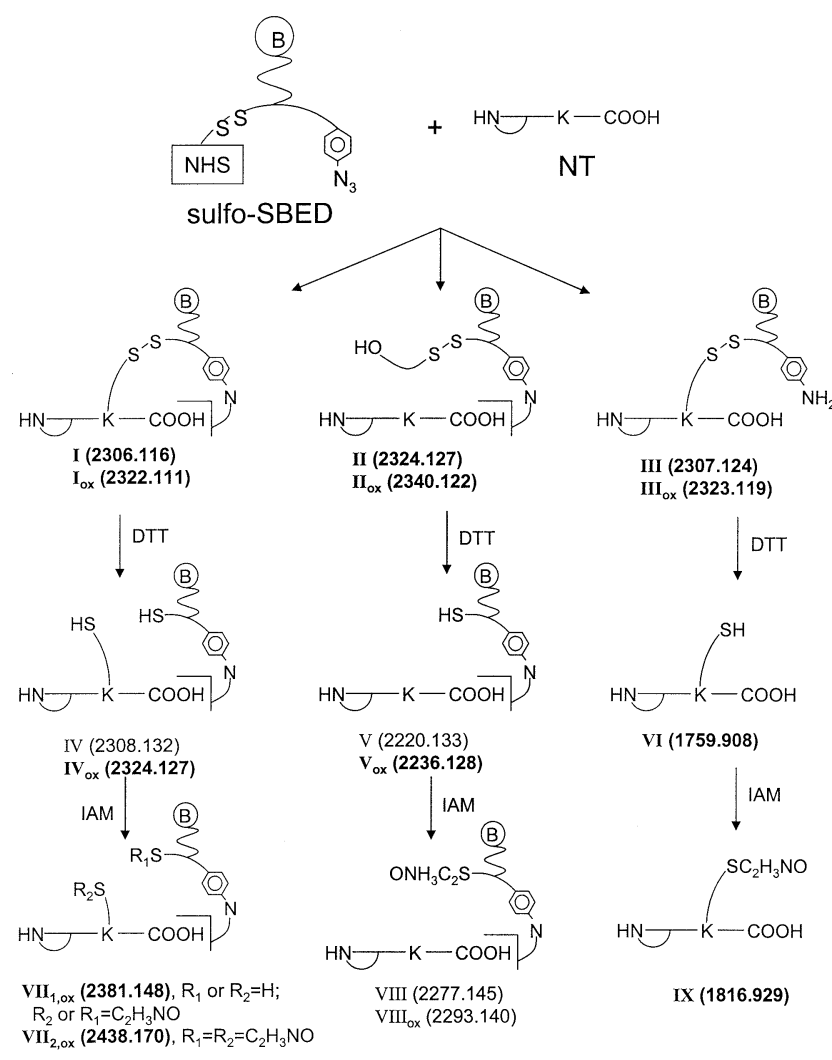

Scheme 1. Reaction of sulfo-SBED with neurotensin (NT). B = biotin; NHS = N-hydroxysuccinimide, DTT $=$ dithiothreitol, IAM $=$ iodoacetamide. The "ox" subscript indicates addition of an O-atom to a species. Bold numbers represent structures consistent with observed peaks in Figure 1. Monoisotopic, neutral masses are listed in parentheses for each structure. rotensin species. Figure 1 shows MALDI-TOF mass spectra of (1a) products of the reaction of sulfo-SBED with neurotensin, (1b) DTT reduction of this reaction mixture, and (1c) iodoacetamide derivatization of the reduced species shown in (1b). Structures from Scheme 1 that are consistent with observed peaks are indicated in Figure 1. Most features in these spectra can be assigned as unreacted neurotensin, or as complete or incomplete intramolecular crosslinking of neurotensin by sulfo-SBED. Unreacted neurotensin (calculated monoisotopic $\left.[\mathrm{M}+\mathrm{H}]^{+}=1672.92\right)$ is visible in Figure 1a and $b$, but was not detected when the amount of sulfo-SBED was doubled (data not shown).

The two most abundant peaks in Figure 1a correspond to products predicted in Scheme 1, indicating that the NHS and arylazide reactions proceeded efficiently. The intense peak at $m / z 2323.1$ in Figure 1a corresponds to $\mathbf{I}_{\mathbf{o x}}, \mathbf{I I}$, or $\mathbf{I I I}_{\mathbf{o x}}$, or some combination of these species. On DTT reduction, $\mathbf{I}_{\mathbf{o x}}$ would yield $\mathbf{I V}_{\mathbf{o x}}$ for which a peak is observed at $m / z 2325.1$ in Figure 1b. Treatment with iodoacetamide yielded peaks at $\mathrm{m} / \mathrm{z}$ 2382.2 and 2439.2 in Figure 1c. These two peaks correspond to addition of one and two carbamidomethyl groups $\left(\mathrm{C}_{2} \mathrm{H}_{3} \mathrm{NO}\right.$; $\left.57 \mathrm{Da}\right)$, respectively, to $\mathbf{I V}_{\mathbf{o x}}$, which contains two free sulfhydryl groups, to form $\mathrm{VII}_{\mathbf{1}, \mathbf{o x}}$ and $\mathrm{VII}_{2, \mathrm{ox}}$. II would yield $\mathbf{V}$ on reduction; no corresponding peak occurs in Figure $1 \mathrm{~b}$. III $_{\mathbf{o x}}$ on reduction would yield VI, which is the most abundant peak in Figure 1b. The corresponding iodoacetamide derivative, IX, is the most abundant peak in Figure 1c. The species observed at $m / z 2341.2$ in Figure $1 \mathrm{a}$ is consistent with $\mathbf{I I}_{\mathbf{o x}}$; reduction with DTT would yield $\mathbf{V}_{\mathbf{o x}}$, for which a peak at $m / z 2237.1$ is observed in Figure 1b, although no

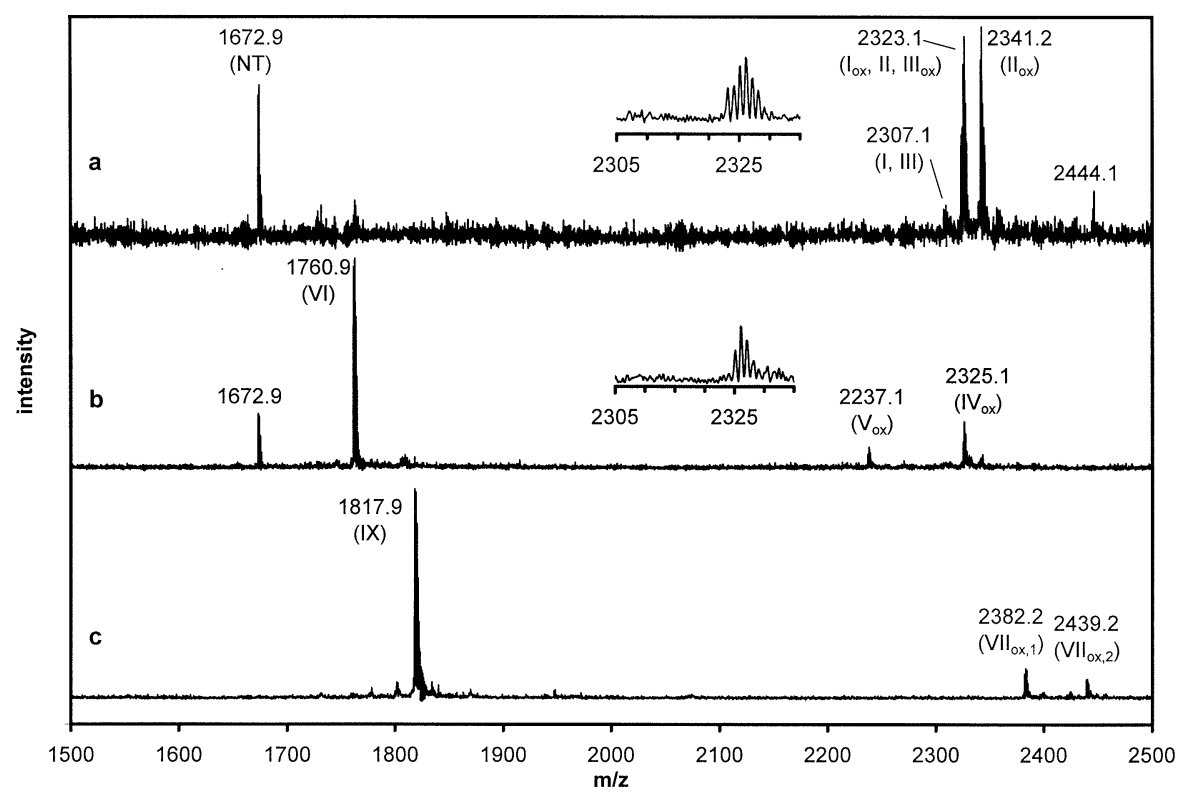

Figure 1. MALDI-TOF mass spectra of (a) products of reaction of $250 \mathrm{nmol}$ sulfo-SBED and $60 \mathrm{nmol}$ neurotensin, (b) reduction of the product by DTT, and (c) reaction of free sulfhydryls with iodoacetamide. The amine-NHS reaction was performed under subdued light for $45 \mathrm{~min}$, while the photoactivated reaction was subsequently performed for 90 min with $365 \mathrm{~nm}$ irradiation. 


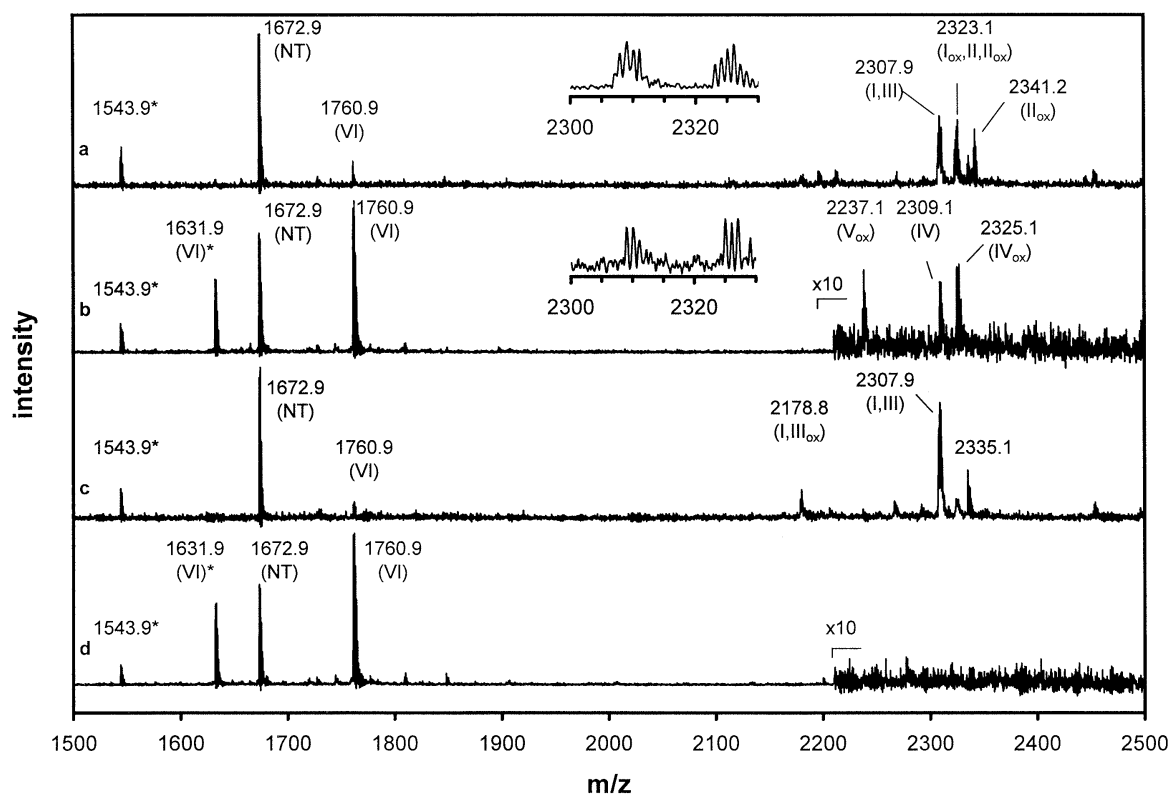

Figure 2. MALDI-TOF mass spectra of products of reaction of $114 \mathrm{nmol}$ sulfo-SBED and $60 \mathrm{nmol}$ neurotensin (a) 15 min UV irradiation, (b) reduction of the 15 min UV reaction product with DTT, (c) 0 min UV irradiation, (d) reduction of the 0 min UV reaction product with DTT. Peaks marked with an asterisk are due to an impurity in the neurotensin sample with $m / z 1543.9$, and reaction products of this impurity.

corresponding carbamidomethyl derivative is seen in Figure 1c. In addition to the two major peaks observed in Figure 1a, a faint signal above background at $\mathrm{m} / \mathrm{z}$ 2307.1 can be assigned either as I or III, since these species differ in mass by only $1 \mathrm{Da}$, and the observed distribution of peaks spaced by $1 \mathrm{Da}$ is wider than the predicted ${ }^{12} \mathrm{C}$ and ${ }^{13} \mathrm{C}$ isotope pattern for a single species of this size (see insets in Figure 1). On reduction by DTT, I would be converted to IV, which is $2 \mathrm{Da}$ heavier. However, IV is not observed in Figure $1 \mathrm{~b}$, which is not surprising given the low $\mathrm{S} / \mathrm{N}$ for the $\mathbf{I} / \mathrm{III}$ peak in Figure 1a. III would be reduced to VI, which, although observed as an intense peak in Figure 1b, probably originates mainly from the more abundant III $_{\text {ox }}$ (vide supra). The $m / z 2444.1$ peak in Figure 1a is not assigned.

Figure 2 shows mass spectra resulting from shorter UV irradiation times. Peaks corresponding to unreacted neurotensin, the expected crosslinking product $\mathbf{I}$, its oxidized counterpart $\mathbf{I}_{\mathbf{o x}}$, and "single-ended" sulfoSBED addition (II, $\mathbf{I I}_{\mathbf{o x}}, \mathbf{I I I}$ and $\mathbf{I I I}_{\mathbf{o x}}$ ) are seen in Figure 2a, for which UV irradiation time was $15 \mathrm{~min}$. (Note in Figure 2 that a peptide near $\mathrm{m} / \mathrm{z} 1543$ was present as a contaminant, and exhibits reaction products similar to those observed for neurotensin with corresponding peaks marked in the figure by asterisks.) Reduction of this product with DTT yielded the spectrum shown in Figure $2 \mathrm{~b}$. The peaks in Figure $2 \mathrm{~b}$ at $\mathrm{m} / \mathrm{z} 2309.1$ and 2325.1, shifted by 2 Da from $\mathbf{I}$ and $\mathbf{I}_{\mathbf{o x}}$ in Figure 2a, appear to be fully-crosslinked products; see the insets to Figure $2 a$ and $b$. The mass spectrum resulting from the "zero" time UV exposure is shown in Figure 2c. Peaks consistent with I or III $(\mathrm{m} / \mathrm{z} 2307.9), \mathbf{I}_{\mathbf{o x}}, \mathbf{I I}$, or $\mathbf{I I I}_{\mathbf{o x}}(\mathrm{m} / \mathrm{z}$ 2325.0) and an unassigned peak at $m / z$ 2335.1, also observed after UV exposures of 90 min (Figure 1a) or 15 min (Figure 2a), are observed. However, on reduction with DTT, Figure $2 d$ shows that all these peaks from the "zero" UV exposure shift by $>>2 \mathrm{Da}$, suggesting that they were products III and III $_{\mathbf{o x}}$ resulting from singleended reaction of the NHS moiety of the crosslinker. The remaining peaks at $m / z 2309.1$ and 2325.1 in Figure $2 \mathrm{~b}$ that both depend on the presence of UV, and shift by $2 \mathrm{Da}$ on DTT reduction, are thus likely to be authentic fully-crosslinked products. The $15 \mathrm{~min}$ UV exposure appears to decrease the degree of oxidation, as evidenced by the increase of intensity at $\mathrm{m} / \mathrm{z} 2309.1$ versus 2325.1 in Figure $2 b$ compared to Figure $1 b$.

The data in Figures 1 and 2 show the occurrence of at least two side reactions to the desired crosslinking. A "single-ended" reaction, in which only the amine-reactive moiety of sulfo-SBED attaches to the lysine side chain of neurotensin, apparently leads to the predominant product III (or III $_{\mathbf{o x}}$ ). On reduction, this product yields VI at $\mathrm{m} / \mathrm{z} 1760.9$, which is the most abundant peak in spectra obtained for 0,15 , and $90 \mathrm{~min} U V$ exposures, as shown in Figure $2 \mathrm{~d}, \mathrm{~b}$, and $1 \mathrm{~b}$, respectively. The arylazide portion of the crosslinker does not attach to the neurotensin in this side reaction. As the "IV/VI ratio" column of Table 1 shows, varying the time of UV exposure from 15 to 90 min did not appear to increase the yield of the fully-crosslinked product in the photoreaction step, suggesting that the photoreaction proceeds rapidly to produce either the desired fully-crosslinked product or a side reaction product 
Table 1. Peak area ratios for DTT-treated crosslinking and side reaction products

\begin{tabular}{lccc}
\hline $\begin{array}{l}\text { UV exposure } \\
\text { time (min.) }\end{array}$ & IV $/$ I ratio $^{\mathrm{a}}$ & IV/IV $_{\text {ox }}$ ratio $^{\mathrm{a}}$ & Figure \\
\hline \hline 0 & 0.013 & Not observed & $2 \mathrm{~d}$ \\
15 & 0.050 & 0.79 & $2 \mathrm{~b}$ \\
90 & 0.048 & 0.24 & $1 \mathrm{~b}$ \\
\hline
\end{tabular}

aPeaks integrated over 5 (VI) or 7 (IV, IV ox $)$ Da range around monoisotopic peak.

such as III. Any such photoreaction side product that does not create a bond to the peptide will, on reduction, yield Structure VI. The second major side reaction, oxidation, appears to occur with a yield equal to or greater than the fully crosslinked product. The extent of oxidation appears to be increased by increasing the duration of UV exposure, as shown in the "IV/IV ${ }_{\text {ox }}$ " column of Table 1. Peaks in Figures 1 and 2 corresponding to species such as I, II, III, IV, V, and VII that incorporate the portion of the crosslinker containing the biotin and arylazide moieties exhibit +16 Da satellites, suggesting that this part of the sulfo-SBED molecule is the site of oxidation. The site of oxidation does not appear to be on the neurotensin peptide itself. The fact that satellite peaks at $+16 \mathrm{Da}$ are not observed for the $m / z 1760$ peak (VI), which contains a potentially oxidizable -SH group, supports the assignment of the $\mathrm{m} / \mathrm{z}$ 2323.1 and 2341.2 peaks in Figure 1a either as incorporation of a $16 \mathrm{Da}$ species during the attachment of the arylazide to neurotensin [25], or as oxidation of the biotin sulfur, rather than oxidation of the sulfur atoms involved in the disulfide linkage. Supporting this assignment is the fact that oxidation at a methionine sulfur is often seen in mass spectra of peptides; the oxidized sulfur is part of a thioether moiety in both the biotin group of sulfo-SBED and in the side chain of methionine. Careful degassing of solutions and other experimental refinements could decrease the extent of this oxidation, leading to simpler spectral interpretation and a decreased splitting of the analytical signal among multiple peaks. Other refinements to the crosslinking also should be explored. For instance, despite remaining unreacted neurotensin, a whitish to yellowish precipitate was observed in some reactions, suggesting precipitation of sulfo-SBED, or perhaps excessive crosslinking leading to multimers. It might be possible to distinguish between these two possibilities by including solvents such as DMSO, in which sulfo-SBED is more soluble, in the reaction mixture.

\section{Avidin Capture of Crosslinked Peptides}

To determine whether peptide species containing an affinity-labeled crosslink, such as that introduced by reaction with sulfo-SBED, could be purified from a background of non-labeled peptides, an affinity capture experiment was performed using a mixture of sulfoSBED-derivatized neurotensin and a tryptic digest of bovine hemoglobin. The affinity capture matrix was

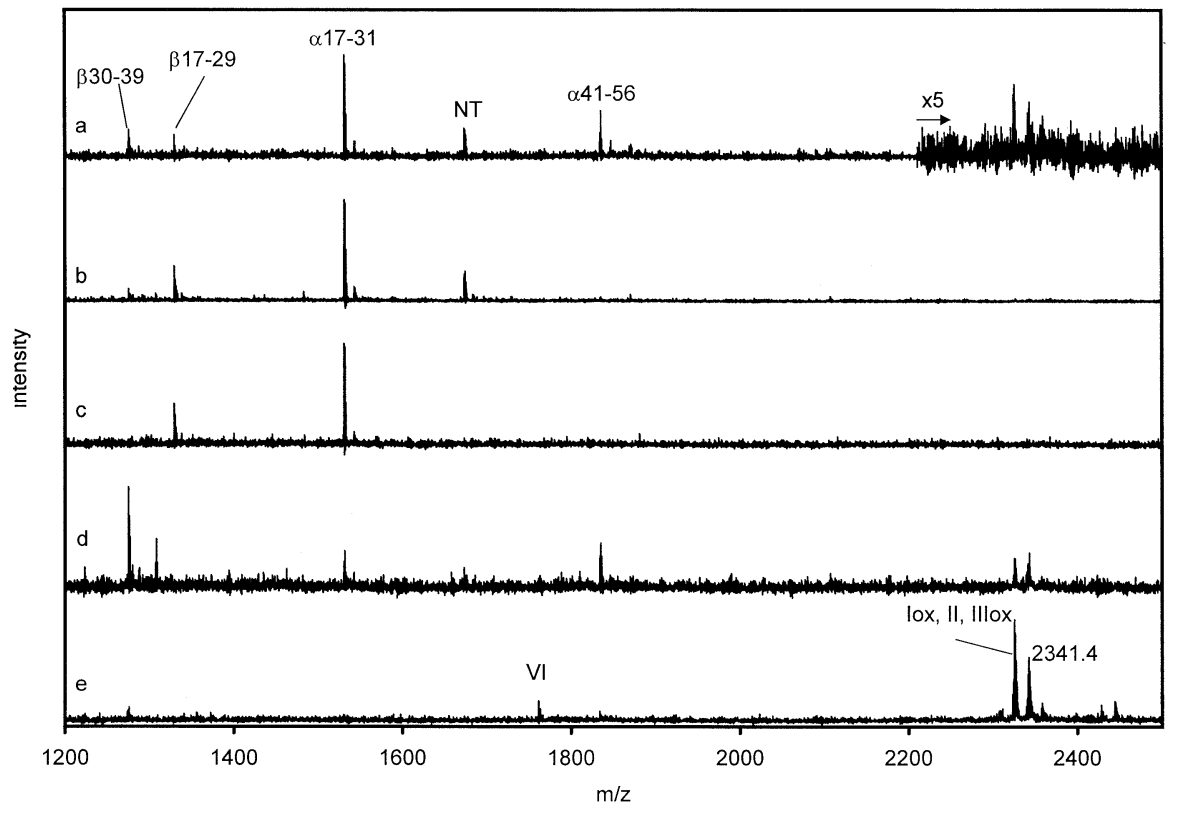

Figure 3. Avidin affinity purification of sulfo-SBED crosslinked neurotensin from mixture of hemoglobin tryptic digest peptides. Sample was in a $100 \mu \mathrm{L}$ volume at $2 \mu \mathrm{M}$ total neurotensin and $\sim 0.3 \mu \mathrm{M}$ in each hemoglobin peptide. (a) Before separation, (b) supernatant after incubation with avidin resin, (c) supernatant from phosphate buffer wash, (d) supernatant from wash with $20 \%$ methanol in $50 \mathrm{mM}$ ammonium bicarbonate, (e) eluent from avidin beads. Peaks corresponding to hemoglobin digest peptides are labeled with the amino acid residue numbers in the $\alpha$ or $\beta$ chain; unreacted neurotensin is marked NT. 
avidin-derivatized beads, which were incubated with the samples over a $3 \mathrm{~h}$ time period with gentle mixing to maximize capture of biotinylated species while minimizing the surface area on which loss of sample could occur. Figure 3 shows MALDI-TOF mass spectra obtained at various stages of the avidin separation. The spectrum in Figure 3a shows a number of peaks assignable as tryptic peptides from hemoglobin, underivatized neurotensin at $m / z 1672.9$, and weak signals corresponding to sulfo-SBED-derivatized neurotensin at $\mathrm{m} / \mathrm{z}$ $2324.2\left(\mathbf{I}_{\mathbf{o x}}, \mathbf{I I}_{\mathbf{o x}}\right.$, or $\left.\mathbf{I I I}\right)$ and $m / z 2341.3\left(\mathbf{I I}_{\mathbf{o x}}\right)$. After incubation with avidin beads, only underivatized neurotensin and hemoglobin digest peaks were observed in the supernatant (Figure 3b). A wash of the avidin beads with phosphate buffer yielded a spectrum, Figure 3c, that showed only hemoglobin digest peaks. A subsequent wash with $20 \%$ methanol in $50 \mathrm{mM}$ aqueous ammonium bicarbonate [26] showed (Figure 3d) continuing elution of hemoglobin digest peptides, but also some sulfo-SBED-derivatized neurotensin at $\mathrm{m} / \mathrm{z} 2325.0$ and 2342.9. Finally, Figure 3e shows the MALDI spectrum of the solution used to elute biotinylated species from the beads, $50 \%$ acetonitrile in aqueous $0.4 \%$ trifluoroacetic acid; this spectrum contains predominantly the sulfo-SBED-derivatized neurotensin peaks observed weakly in the pre-avidin mixture, Figure $3 a$, plus a small peak at $\mathrm{m} / \mathrm{z} 1760.9$ corresponding to cleavage of the disulfide bond of the sulfo-SBED, a phenomenon previously reported under MALDI conditions [27]. These results suggest that the batch avidin bead separation enriches the biotin-containing peptide species fairly efficiently, with little non-specific binding. A semi-quantitative estimate of the enrichment of biotinylated species in this procedure can be obtained from ratios of peak areas in Figure 3a and e. The ratio of the areas of the $\mathrm{m} / \mathrm{z} 2322$ peak to the $\mathrm{m} / \mathrm{z} 1274$ hemoglobin digest peak ( $(330-39)$ is 1.2 in Figure 3a, and increases to 11 in Figure 3e. Note that the very weak $\mathrm{m} / \mathrm{z} 1274$ peak is the only hemoglobin digest peak observed in Figure 3e after the affinity isolation, so this estimate of the enrichment is probably a lower limit.

The results shown in Figure 3 are encouraging, even though the relative amounts of the various components of the mixture may not reflect those that would be encountered in a protein crosslinking experiment. Assuming complete and uniform recovery in the purification of the hemoglobin tryptic peptides, the $100 \mu \mathrm{L}$ solution undergoing affinity capture was $\sim 0.3 \mu \mathrm{M}$ in each hemoglobin peptide, for a total of $\sim 2 \mu \mathrm{g}$ of hemoglobin tryptic peptides. The concentration of biotinylated peptides is more difficult to estimate, since the yield of the crosslinking reaction was not easily measured. If no crosslinking had been performed, the neurotensin concentration in the capture sample would have been $\sim 2 \mu \mathrm{M}$. In the crosslinking reaction from which this avidin capture sample was derived, as Figure 3a shows, unreacted neurotensin was detected prior to avidin capture; $2 \mu \mathrm{M}$ is thus an upper limit for the concentration of biotinylated sulfo-SBED derivat- ized neurotensin. A $1 \mu \mathrm{M}$ concentration would correspond to $\sim 230 \mathrm{ng}$ of sulfo-SBED derivatized neurotensin, or about one ninth the mass of hemoglobin tryptic peptides estimated to be in the sample. In experiments involving crosslinking of proteins or protein complexes, this ratio would be less favorable, but the results presented in Figure 3 nonetheless demonstrate an enrichment of biotinylated species.

Several factors improved the overall yield and specificity of the avidin isolation. The experiments were performed using a monomeric avidin resin, which retains biotin less strongly than native tetrameric avidin and therefore allows gentler elution [26]. Initial experiments following a protocol similar to that provided by the resin manufacturer, but scaled down in volume and implemented as a batch (rather than column) method, resulted in significant non-specific binding to the beads (data not shown). In addition to the biotin blocking step in the manufacturer's protocol, a second blocking step using bovine serum albumin further reduced nonspecific binding of non-biotinylated peptides by the avidin beads, as did incorporation of a $20 \%$ methanol/50 $\mathrm{mM}$ bicarbonate wash [26]. Additional washes of the beads with phosphate buffer may also be useful for further decreasing non-specific binding (data not shown.) Based on the manufacturer's stated biotin binding capacity, the quantity of capture beads added was sufficient to bind an amount slightly greater (1.2fold) than the amount of neurotensin (and therefore any biotinylated sulfo-SBED derivative of neurotensin) in the sample. Adjusting the amount of beads would be guided by maximizing capture of biotinylated species while minimizing non-specific capture.

\section{Conclusions}

The ability to isolate crosslinked peptides from noncrosslinked peptides would greatly facilitate the use of mass spectrometry for locating chemical crosslinks introduced into proteins and protein complexes. SulfoSBED produces several products in addition to the simple predicted intramolecular crosslink of neurotensin. Knowledge of the identities of these products gained from the simple model system described here will be helpful in interpreting mass spectrometry data from crosslinking experiments on larger proteins or protein complexes, which will contain multiple crosslinking sites. Other biotinylated crosslinkers could be synthesized to accommodate a wider variety of proteins and protein complexes. A biotinylated homobifunctional crosslinker with two NHS groups, both reactive toward primary amines on proteins [21], is one such possibility; such a reagent would reduce the non-specificity introduced by the arylazide group of sulfo-SBED. Preliminary evidence suggests that tandem mass spectrometry experiments, such as MS-MS or $\mathrm{MS}^{3}$, can identify the two peptides in a crosslinked pair $[5,10$, 28]. Extension of well-established techniques, such as cross-correlation-based algorithms for matching tan- 
dem MS data of peptides to protein databases [29], or de novo sequence determination methods [30], could prove feasible for analysis of crosslinked peptide pairs.

\section{Acknowledgments}

The authors gratefully acknowledge helpful discussions with Robert Hettich and Joshua Sharp. This research was sponsored by the U.S. Department of Energy, Office of Biological and Environmental Research, and the Laboratory Directed Research and Development Program of Oak Ridge National Laboratory (ORNL). ORNL is managed by UT-Battelle, LLC for the U.S. Department of Energy under contract no. DE-AC05-00OR22725.

\section{References}

1. Wong, S. S. Chemistry of Protein Conjugation and Crosslinking, CRC Press, Inc.: Boca Raton, FL, 1991.

2. Lutter, L. C.; Kurland, C. G. Chemical Determination of Protein Neighborhoods in a Cellular Organelle. Mol. Cell. Biochem. 1975, 7, 105-116.

3. Rappsilber, J.; Siniossoglou, S.; Hurt, E. C.; Mann, M. A Generic Strategy to Analyze the Spatial Organization of MultiProtein Complexes by Crosslinking and Mass Spectrometry. Anal. Chem. 2000, 72, 267-275.

4. Mattson, G.; Conklin, E.; Desai, S.; Nielander, G.; Savage, M. D.; Morgensen, S. A Practical Approach to Crosslinking. Mol. Biol. Rep. 1993, 17, 167-183.

5. Young, M. M.; Tang, N.; Hempel, J. C.; Oshiro, C. M.; Taylor, E. W.; Kuntz, I. D.; Gibson, B. W.; Dollinger, G. High Throughput Protein Fold Identification by Using Experimental Constraints Derived from Intramolecular Crosslinks and Mass Spectrometry. Proc. Natl. Acad. Sci. U.S.A. 2000, 97, 5802-5806.

6. Havel, T. F.; Crippen, G. M.; Kuntz, I. D. Effects of Distance Constraints on Macromolecular Conformation. II. Simulation of Experimental Results and Theoretical Predictions. Biopolymers 1979, 18, 73-81.

7. Cohen, F. E.; Sternberg, M. J. E. On the Use of Chemically Derived Distance Constraints in the Prediction of Protein Structure with Myoglobin as an Example. J. Mol. Biol. 1980, 137, 9-22.

8. Yang, T.; Horejsh, D. R.; Mahan, K. J.; Zaluzec, E. J.; Watson, J. T.; Gage, D. A. Mapping Crosslinking Sites in Modified Proteins with Mass Spectrometry: An Application to Crosslinked Hemoglobins. Anal. Biochem. 1996, 242, 55-63.

9. Manning, L. R.; Morgan, S.; Beavis, R. C.; Chait, B. T.; Manning, J. M.; Hess, J. R.; Cross, M.; Currell, D. L.; Marini, M. A.; Winslow, R. M. Preparation, Properties, and Plasma Retention of Human Hemoglobin Derivatives: Comparison of Uncrosslinked Carboxymethylated Hemoglobin with Crosslinked Tetrameric Hemoglobin. Proc. Natl. Acad. Sci. U.S.A. 1991, 88, 3329-3333.

10. Chen, T.; Jaffe, J. D.; Church, G. M. Algorithms for Identifying Protein Crosslinks via Tandem Mass Spectrometry. J. Comput. Biol. 2001, 8, 571-583.

11. Bayan, N.; Therisod, H. Photoaffinity Crosslinking of Acyl Carrier Protein to Escherichia coli Membranes. Biochim. Biophys. Acta 1992, 1123, 191-197.

12. Muller, D. R.; Schindler, P.; Towbin, H.; Wirth, U.; Voshol, H.; Hoving, S.; Steinmetz, M. O. Isotope Tagged Cross Linking Reagents. A New Tool in Mass Spectrometric Protein Interaction Analysis. Anal. Chem. 2001, 73, 1927-1934.

13. Pearson, K. M.; Pannell, L. K.; Fales, H. M. Intramolecular Crosslinking Experiments on Cytochrome $c$ and Ribonuclease A Using an Isotope Multiplet Method. Rapid Commun. Mass Spectrom. 2002, 16, 149-159.

14. Taverner, T.; Hall, N. E.; O'Hair, R. A. J.; Simpson, R. J. Characterization of an Antagonist Interleukin-6 Dimer by
Stable Isotope Labeling, Crosslinking, and Mass Spectrometry. J. Biol. Chem. 2002, 277, 46487-46492.

15. Chen, X. H.; Chen, Y. H.; Anderson, V. E. Protein Crosslinks: Universal Isolation and Characterization by Isotopic Derivatization and Electrospray Ionization Mass Spectrometry. Anal. Biochem. 1999, 273, 192-203.

16. Chen, X.; Eswaran, D.; Smith, M. A.; Perry, G.; Anderson, V. E. Universal Isolation of Crosslinked Peptides: Application to Neurofibrillary Tangles. Bioconj. Chem. 1999, 10, 112-118.

17. Back, J. W.; Notenboom, V.; de Koning, L. J.; Muijsers, A. O.; Sixma, T. K.; De Koster, C. G.; de Jong, L. Z. Identification of Crosslinked Peptides for Protein Interaction Studies Using Mass Spectrometry and O-18 Labeling. Anal. Chem. 2002, 74, 4417-4422.

18. Back, J. W.; Hartog, A. F.; Dekker, H. L.; Muijsers, A. O.; de Koning, L. J.; de Jong, L. A New Crosslinker for Mass Spectrometric Analysis of the Quaternary Structure of Protein Complexes. J. Am. Soc. Mass Spectrom. 2001, 12, 222-227.

19. Back, J. W.; Sanz, M. A.; de Jong, L.; de Koning, L. J.; Nijtmans, L. G. J.; De Koster, C. G.; Grivell, L. A.; Van der Spek, H.; Muijsers, A. O. A Structure for the Yeast Prohibitin complex: Structure Prediction and Evidence from Chemical Crosslinking and Mass Spectrometry. Prot. Sci. 2002, 11, 2471-2478.

20. Wine, R. N.; Dial, J. M.; Tomer, K. B.; Borchers, C. H. Identification of Components of Protein Complexes Using a Fluorescent Photo-Crosslinker and Mass Spectrometry. Anal. Chem. 2002, 74, 1939-1945.

21. Trester-Zedlitz, M.; Kamada, K.; Burley, S. K.; Fenyo, D.; Chait, B. T.; Muir, T. W. A Modular Crosslinking Approach for Exploring Protein Interactions. J. Am. Chem. Soc. 2003, 125, 2416-2425.

22. Anderson, G. W.; Zimmerman, J. E.; Callahan, F. M. The Use of Esters of N-Hydroxysuccinimide in Peptide Synthesis. J. Am. Chem. Soc. 1964, 86, 1839-1842.

23. Pandurangi, R. S.; Katti, K. V.; Barnes, C. L.; Volkert, W. A.; Kuntz, R. R. High Yields of Nitrene Insertion into Unactivated C-H bonds-First Example of X-ray Crystallographic and F-19 NMR Analysis of the Photochemically Produced C-H Inserted Adduct. J. Chem. Soc. Chem. Commun. 1994, 16, 1841-1842.

24. Vorm, O.; Roepstorff, P.; Mann, M. Improved Resolution and Very High Sensitivity in MALDI TOF of Matrix Surfaces Made by Fast Evaporation. Anal. Chem. 1994, 66, 3281-3287.

25. Chen, X. R.; Siems, W. F.; Asbury, G. R.; Yount, R. G. Fingerprint Patterns from Laser-Induced Azido Photochemistry of Spin-Labeled Photoaffinity ATP Analogs in MatrixAssisted Laser Desorption/Ionization Mass Spectrometry. J. Am. Soc. Mass Spectrom. 1999, 10, 1337-1340.

26. Griffin, T. J.; Gygi, S. P.; Rist, B.; Aebersold, R.; Loboda, A.; Jilkine, A.; Ens, W.; Standing, K. G. Quantitative Proteomic Analysis Using a MALDI Quadrupole Time-of-Flight Mass Spectrometer. Anal. Chem. 2001, 73, 978-986.

27. Patterson, S. D.; Katta, V. Prompt Fragmentation of DisulfideLinked Peptides During Matrix-Assisted Laser Desorption Ionization Mass Spectrometry. Anal. Chem. 1994, 66, 3727-3732.

28. Hurst, G. B.; Sega, M.; Stephenson, J. L., Jr.; Lankford, P. K.; Lewis, J. A. Tandem Mass Spectrometry Analysis of Crosslinked Proteins and Protein Complexes. Proceedings of the 50th ASMS Conference on Mass Spectrometry and Allied Topics; Orlando, FL, June 2002.

29. Eng, J. K.; McCormack, A. L.; Yates, J. R. III. An Approach to Correlate Tandem Mass Spectral Data of Peptides with Amino Acid Sequences in a Protein Database. J. Am. Soc. Mass Spectrom. 1994, 5, 976-989.

30. Taylor, J. A.; Johnson, R. S. Implementation and Uses of Aautomated de Novo Peptide Sequencing by Tandem Mass Spectrometry. Anal. Chem. 2001, 73, 2594-2604. 